\title{
Confrontation, Consolidation, and Recognition: The Oocyte's Perspective on the Incoming Sperm
}

\author{
David Miller \\ Institute of Cardiovascular and Metabolic Medicine (LICAMM), LIGHT Laboratories, University of Leeds, \\ Leeds, LS2 9JT West Yorkshire, United Kingdom \\ Correspondence: d.miller@leeds.ac.uk
}

From the oocyte's perspective, the incoming sperm poses a significant challenge. Despite (usually) arising from a male of the same species, the sperm is a "foreign" body that may carry with it additional, undesirable factors such as transposable elements (mainly retroposons) into the egg. These factors can arise either during spermatogenesis or while the sperm is moving through the epididymis or the female genital tract. Furthermore, in addition to the paternal genome, the sperm also carries its own complex repertoire of RNAs into the egg that includes mRNAs, IncRNAs, and sncRNAs. Last, the paternal genome itself is efficiently packaged into a protamine (nucleo-toroid) and histone (nucleosome)-based chromatin scaffold within which much of the RNA is embedded. Taken together, the sperm delivers a far more complex package to the egg than was originally thought. Understanding this complexity, at both the compositional and structural level, depends largely on investigating sperm chromatin from both the genomic (DNA packaging) and epigenomic (RNA carriage and extant histone modifications) perspectives. Why this complexity has arisen and its likely purpose requires us to look more closely at what happens in the oocyte when the sperm gains entry and the processes that then take place preparing the paternal (and maternal) genomes for syngamy.

In nature, it is not an absolute that an egg has to be fertilized by a sperm before it becomes competent to undergo cleavage and begin embryonic development. There are examples of natural parthenogenesis in many clades in which egg development from haploid or even diploid zygotes occurs without any genetic contribution by the male (Fujita and Moritz 2009; Buric et al. 2011). There are, however, no examples of naturally occurring parthenogenesis in mam- mals. When such development does occasionally take place, for example, due to fertilization by the sperm followed by loss of the paternal genome, it is always nonviable, rarely proceeding beyond activation of the embryonic genome. But, mouse parthenotes have been created in the laboratory by introducing a female pronucleus into MII staged mouse eggs, activating the eggs and then transferring cleavage stage embryos into surrogate females (Kono et al.

Editors: Diana W. Bianchi and Errol R. Norwitz

Additional Perspectives on Molecular Approaches to Reproductive and Newborn Medicine available

at www.perspectivesinmedicine.org

Copyright (C) 2015 Cold Spring Harbor Laboratory Press; all rights reserved; doi: 10.1101/cshperspect.a023408

Cite this article as Cold Spring Harb Perspect Med 2015;5:a023408 
D. Miller

2004). The sole manipulation performed on the second maternal pronuclei before their introduction to the eggs (by injection) was to their H19, Igf2 locus, which was engineered to carry a paternal imprint. Although live birth rates were very low, normal pups were born and moreover, offspring were also reported. Parthenogenetic mice have also been derived from parthenogenetically derived embryonic stem cells at a slightly higher efficiency (Chen et al. 2009).

These elegant experiments show that even in mammalian zygotes, provided they are diploid and that an "appropriate" imprinting balance is established between the contributing genomes, a paternalgenome at fertilization is not essential. So, in addition to the development of sexual reproduction, genetic forces have been at work ensuring that a male genome is required before reproduction can take place. At first sight, it would appear that in placental mammals at least, one of these forces has been genomic imprinting, which probably arose as a compromise between competing female and male interests that sought to maximize fetal growth against the maternal need to control placental overgrowth (for recent reviews, see Abu-Amero et al. 2006; Moore 2012; Jurkowska and Jeltsch 2013). Molar pregnancy (duplication of the paternal genome with concomitant loss of the maternal genome) with trophoblastic overgrowth and little or no embryonic tissue is a good example of how finely balanced the control has become. However, it can be argued that the example of mammalian parthenotes alongside the absence of genomic imprinting in clades in which parthenogenesis occurs naturally suggests that genomic imprinting has arisen more to prevent parthenogenesis than to ensure that a male genome is required to permit embryonic development. A male sex with sperm is just one way of generating and transmitting genetic diversity through sexual reproduction.

As a paternal genome is not strictly necessary for embryonic development to take place and assuming that parental genomic imprinting evolved to balance the sexually preferable "abolition" of parthenogenic development against the inevitable competition for male versus female interests in the growing embryo, what en- sures that a male genome is required? The answer should take account of the potentially serious consequences for the female of uncontrolled paternally initiated growth that might be expected to select against a distinctly male contribution (hydatidform moles). Indeed, some species of poecilid fish may already have gone down this road, dispensing with males altogether, except as occasional generators of the sperm required to fertilize their eggs (Quattro et al. 1992). The sperm, however, make no genetic contribution to the zygotes; amazon mollies, for example, exist almost exclusively as triploid gynogenetic clones.

One possible scenario is that to facilitate and promote the proliferation of male fitness genes into subsequent generations, males have developed a strategy to ensure that those genes have access to and will be accommodated by the female egg. The strategy could form the basis for the complex packaging of the paternal genome, in which discrete domains packaged by protamines coexist alongside blocks of nucleosomally packaged DNA (for recent reviews, see Miller et al. 2010; Johnson et al. 2011a; Jenkins and Carrell 2012; Bjorndahl and Kvist 2014; Casas and Vavouri 2014). An equally complex repertoire of RNAs is embedded within and/ or is in close association with the chromatin (see Fig. 1) (for a recent review, see Hamatani 2012). In this article, I shall provide evidence for and argue that the paternal payload to the egg includes an epigenetic signature written in both the higher order packaging of the genome itself (into nucleotoroids and nucleosomes) and in the lower order modifications of some histones within those nucleosomes and the RNAs that co-associate with the paternal genome. This signature provides a "bona fide" that is "read" by maternal factors shortly after the sperm enters the ooplasm and that enables the egg's machinery to pass a checkpoint, permitting the paternal genome to be processed for syngamy with the maternal genome (see Fig. 2). The checkpoint is likely to occur sometime between completion of meiosis II, which happens on fertilization, and formation of the male pronucleus and certainly before the global activation of the embryonic genome. The sperm 
An Oocyte's Perspective on Incoming Sperm

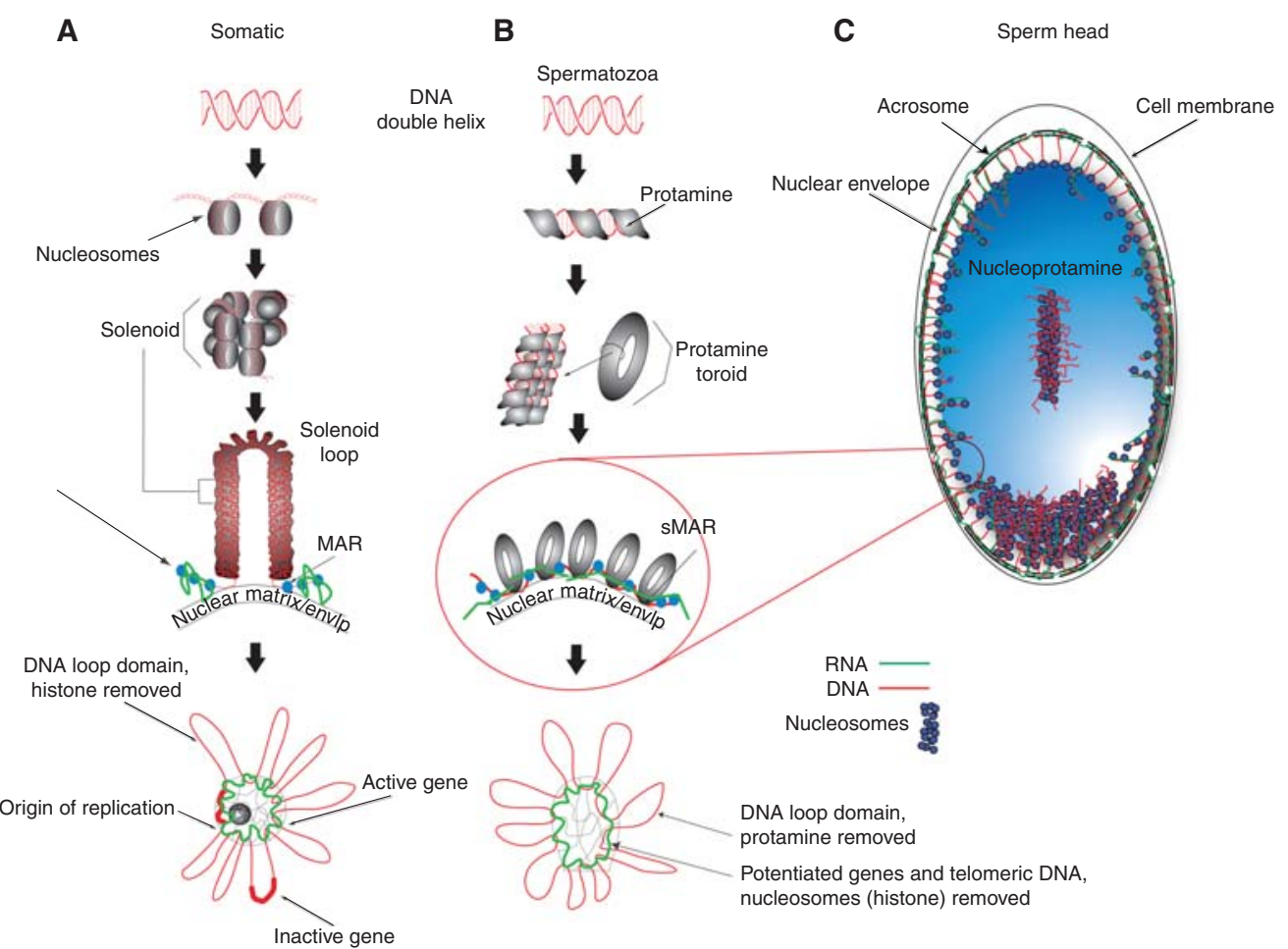

Figure 1. Model for sperm protamine (toroid)/histone (nucleosome) DNA packaging in relation to sperm RNA. The standard model for DNA packaging in the nuclei of somatic cells $(A)$ is based on condensation of DNA into solenoids and then into loops, which are thought to be associated with the nuclear matrix via matrix attachment regions (MAR). Salt-extracted nuclei form halos in which the formerly nucleosomal DNA loops out from the nuclear envelope. Regions being expressed are thought to remain more closely associated with the matrix in which the transcriptional (and DNA replication) machinery lies. In sperm (which are transcriptionally silent) $(B)$, the majority of nucleosome-bound DNA is replaced by protamine toroids that can package the DNA far more efficiently than is possible with solenoids in 30-50 kbp blocks. Low salt extraction of sperm nuclei releases histones with the resultant loops composed mainly of genic DNA (although see Carone et al. 2014 and Samans et al. 2014 for a contrary view). The association between nucleosomes and the nuclear matrix is thought to be conserved in sperm, with one model (Ward 2010) suggesting that sperm retain nucleosome to link toroids and anchor them to the matrix as before. However, we and others have shown that there is far more histone in sperm nuclei than can be accommodated by this model alone. Peripherally located nucleosomes may be associated with telomeric regions (Zalenskaya et al. 2000) and the sperm chromocenter (Govin et al. 2007), with particularly enriched regions in the posterior nucleus ( $C$, and $\mathrm{Li}$ et al. 2008; D. Miller, unpubl.). The RNA is very difficult to resolve completely from DNA, probably because it is embedded in or is in close association with the chromatin (Wykes et al. 1997).

acceptance mechanism is an extension of the confrontation and consolidation hypothesis that can accommodate the control of retroposon activation and expression in nonmammalian gametes (Bourc'his and Voinnet 2010). To build the case, the next section will consider the unique and unusual packaging of sperm DNA; subsequent sections will consider the complex sperm RNA repertoire and will bring the two aspects together into the context of epigenetic programming and the compatibility issue between the incoming sperm and receiving egg.

\section{SPERM DNA PACKAGING}

Mammals have solved the problem of how to package their relatively large genomes into as small a volume as possible during spermatogen- 


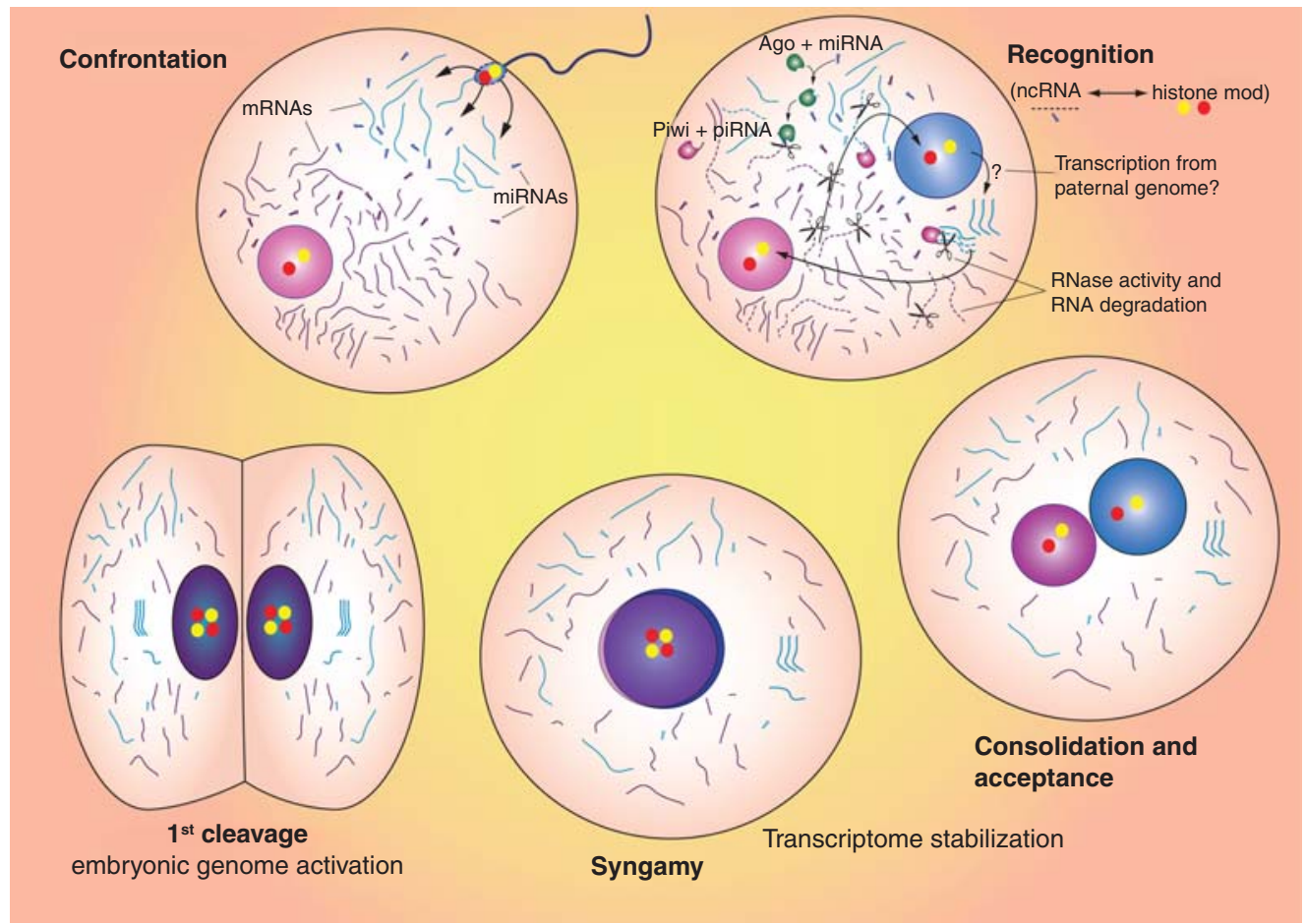

Figure 2. Model for cytoplasmic and genetic compatibility in sperm - egg recognition that embraces and extends the hypothesis of confrontation and consolidation. The sperm is essentially a "foreign" cell that gains entry into the ooplasm and in so doing poses a challenge to the egg (and potential zygote) in relation to the transmission of paternally derived genetic parasites (primarily retroposons and endogenous retrovirus). These are probably dealt with by mechanisms using piRNA and miRNA present in the ooplasm and introduced by the sperm. However, these RNA-based interactions may also have been co-opted into and augmented by chromatin-based signaling using histone modifications (colored spheres) that "scans" the incoming paternal genome for genetic compatibility. Sperm that pass the recognition check for cytoplasmic and genetic compatibility can proceed to syngamy. Pronuclei can form regardless of compatibility but subsequent failure to pass the checks will lead to a failure in embryonic genome activation.

esis by substituting the usual nucleosome-based DNA packaging solution present in all somatic cells and premeiotic spermatocytes with a unique, protamine-based sperm-specific chromatin that is at least twenty times more condensed (Fuentes-Mascorro et al. 2000). The substitution is not unique to mammals; similar protamine-like sperm DNA packaging proteins are found in other species (Eirin-Lopez and Ausio 2009; Kasinsky et al. 2011). They probably all arose independently by frame shift mutations that led to the conversion of lysine (dominant in histones) to arginine (dominant in protamines). Considering the higher efficiency afforded by DNA packaging on protamines
(50 kbp basic packaging on protamine/DNA toroids) compared with nucleosomes (145 bp basic packaging), it follows that that there should be strong selection in favor of retaining protamines in sperm nuclei.

For some time, the substitution was thought to be complete in mammals until reports on the unexpectedly high retention of nucleosomal chromatin in marsupial sperm appeared (Soon and Breed 1996; Soon et al. 1997). In later years, human, bovine, and murine sperm were also shown to retain nucleosomes. Sperm nucleosomes are usually detected by brief digestion of their nuclei with micrococcal nuclease, followed by the resolution of the solubilized DNA 
on agarose gels, in which the typical $145 \mathrm{bp}$ repeating ladder reported from digestion of somatic cell nuclei can be seen following gel electrophoresis and staining (Zalenskaya et al. 2000; Arpanahi et al. 2009). There have been concerns that the observed nucleosome-based ladder is not caused by sperm nucleosomes, but by the nucleosomes from other cell types frequently found in semen and notoriously difficult to exclude altogether from digestion protocols; however, immunocytochemistry with antihistone antibodies has provided good independent evidence for their presence in sperm nuclei (Govin et al. 2007; Li et al. 2008; van der Heijden et al. 2008; Brykczynska et al. 2010; Oliva and Ballesca 2012; Erkek et al. 2013). Interestingly, reports on nonnucleosomal histones in bovine sperm, associating with the perinuclear theca and also with the acrosomal process are available to read, suggesting that two populations of histones persist in sperm; those that are intranuclear and probably contained within DNA-packaging nucleosomes and those that are extranuclear and nonnucleosomal and carry out some other unknown functions (Oko and Maravei 1994; Aul and Oko 2002). Herein, we shall concern ourselves solely with the former (Fig. 1).

What makes the retention of nucleosomes so interesting is that they appear to package distinct regions of DNA, although precisely what those regions are remains highly contentious. The earliest reports were based on Southernblot analysis and suggested that such nucleosome-enriched regions contained genes with some fetal relevance, although the limitations of using just one or two probes made such assumptions somewhat premature (Gatewood et al. 1987, 1990). The development of microarray and subsequently, sequencing technologies has made it possible to far more thoroughly characterize the composition of micrococcal nuclease (MNase) or salt extracted and endonuclease digested DNA (Arpanahi et al. 2009; Hammoud et al. 2009). Until recently, there appeared to be a consensus between the numerous reports looking at the composition of nucleosomal compartments in human and murine sperm chromatin. These all provided evidence that the nuclease soluble DNA was enriched in GC-rich exonic sequences with a strong developmental ontology (Arpanahi et al. 2009; Hammoud et al. 2009; Brykczynska et al. 2010; Vavouri and Lehner 2011; Castillo et al. 2014). The suggestion that the (protein) encoding genome (or critical parts thereof ) were largely held back from being protaminated is intriguing as it suggests some postfertilization function, possibly related to the repackaging of the paternal genome by maternal histones during pronuclear formation (McLay and Clarke 2003; Loppin et al. 2005; Mudrak et al. 2009). DNA digestion "foot printing" of this type reveals important topographical and architectural information on chromatin packaging, which in somatic cell nuclei corresponds with regions that are relatively decondensed (euchromatic) and hence available for transcription compared with regions that are relatively condensed (heterochromatic) and so unavailable for transcription (Cappabianca et al. 1999; Bell et al. 2011). Sperm nuclei are transcriptionally silent, and so this soma-like differential chromatin condensation state most likely arises shortly before transcription shuts down in the early spermatid. This "frozen" chromatin state could reflect either the de novo gene expression program before shut down or reflect a postfertilization function or perhaps even both. In this regard, reports are available suggesting that specific histone marks (for example, permissive and repressive $\mathrm{H} 3$ methylation) on gene promoters distinguishes between regions packaging genes involved in spermatogenesis and genes that are expressed much later in embryogenesis (the HOX gene clusters, for example) (Arpanahi et al. 2009; Saida et al. 2011; Castillo et al. 2014; Ihara et al. 2014). The results from more targeted ChIP-sequencing approaches using antibodies directed against these modified histones generally support these conclusions (Arpanahi et al. 2009; Hammoud et al. 2009; Brykczynska et al. 2010). However, the consensus has recently been challenged by reports suggesting that far from packaging the coding genome, sperm nucleosomes package DNA enriched in noncoding sequences containing repetitive sequences (Carone et al. 2014; Samans et al. 2014). As a narrow example of the divergence between these latest and previous reports, the latter has shown 
retention of nucleosomes in exonic regions of the HOX gene clusters in human sperm, whereas the former suggests these clusters are essentially nucleosome-free and largely protaminated. In my view, these differences are likely to be attributed to differences in the applied methodologies (one report, for example Carone et al. 2014, exposed sperm nuclei to formaldehyde before MNase digestion). Considering that repetitive sequences are by far the most abundant in the genome, it is perhaps not unexpected that they should be strongly represented in sperm nuclease digestion products. The results from nuclei treated with low salt (to extract histones) followed by mild restriction digestion and recovery of the exposed (SRDS) DNA suggested that histone-bound DNA is far more compositionally complex than these later reports indicate. Sequencing data from MNase-digested mononucleosomal DNA and DNA associated with smaller subnucleosomal particles released following low salt extraction of sperm chromatin followed by restriction endonuclease digestion (SRDS) to recover the DNA, showed that the SRDS material had the strongest gene-centric (promoterbiased) content, followed by the subnucleosomal and then the nucleosomal DNA. These data suggest that nuclease accessible regions of sperm euchromatin include a "mix" of nucleosomal and subnucleosomal chromatin, associated mostly with gene promoter elements. The reports suggest that procedures using salt extraction followed by restriction digestion of sperm nuclei (SRDS) that rely on differential chromatin condensation states to "tease out" more relaxed chromatin domains, releases more internucleosomal DNA that is deterministically more likely to be gene-rich by association with gene promoters (Henikoff et al. 2009). Whatever the reasons for the reports suggesting their contrary association (with gene deserts), there is no dissent regarding the delivery of sperm nucleosomes, including their modified histones to the egg (see below and the last section). Suggestions for their roles once in the ooplasm includes acting as nucleation centers for protamine to maternal nucleosome exchange as well as more directed instructions to either prevent or promote expression from paternal alleles in the early cleave-stage embryo (Aoki et al. 1997). Distinguishing between these possibilities is not straightforward, but one recent report using knockout mice with aberrant sperm chromatin packaging leading to overretention of nucleosomes (a commonly encountered finding in human semen analysis) (Sati et al. 2008) showed that the transcriptome of cleavage stage mouse embryos fertilized by mutant versus wild-type sperm were grossly different, although there was no apparent effect on live birth outcome (Ihara et al. 2014).

Regardless of which model is correct (the truth most likely lies somewhere between), reports based on next generation sequencing (NGS) coverage augment the characterization of histones in mature sperm as visualized by immunomicroscopy (Palmer et al. 1990; van der Heijden et al. 2006, 2008; Govin et al. 2007; Li et al. 2008). The presence of modified histones in sperm is also revealing, particularly in relation to the sequences with which they are associated. In this regard, the presence of gene expression "permissive" and "repressive" marks on or close to promoter regions in MNase soluble and histone ChIP-enriched DNA is of interest because of their potential effects in the fertilized egg (Hammoud et al. 2009; Brykczynska et al. 2010; Miller et al. 2010). Certainly, the fate of sperm nucleosomes in the zygote is currently unresolved, although they can be detected in the ooplasm before decondensation. They may persist beyond, although distinguishing paternal marks from the overwhelming dominance of equivalent maternal marks will make the following of their fate in the early embryo highly problematic.

Finally, the available sequencing data suggests that nonnucleosomal DNA in the sperm nucleus, at least in the proximity of more closely examined euchromatic regions, is unlikely to be wholly protamine-bound, if current models for protamine-DNA interaction are correct. An illustration of this can be seen in the original data views obtained on the UCSC browser for HOXD (Fig. 3) (Arpanahi et al. 2009; and see Hammoud et al. 2009). The whole cluster could be accommodated by between two and three protamine toroids (that can package up 


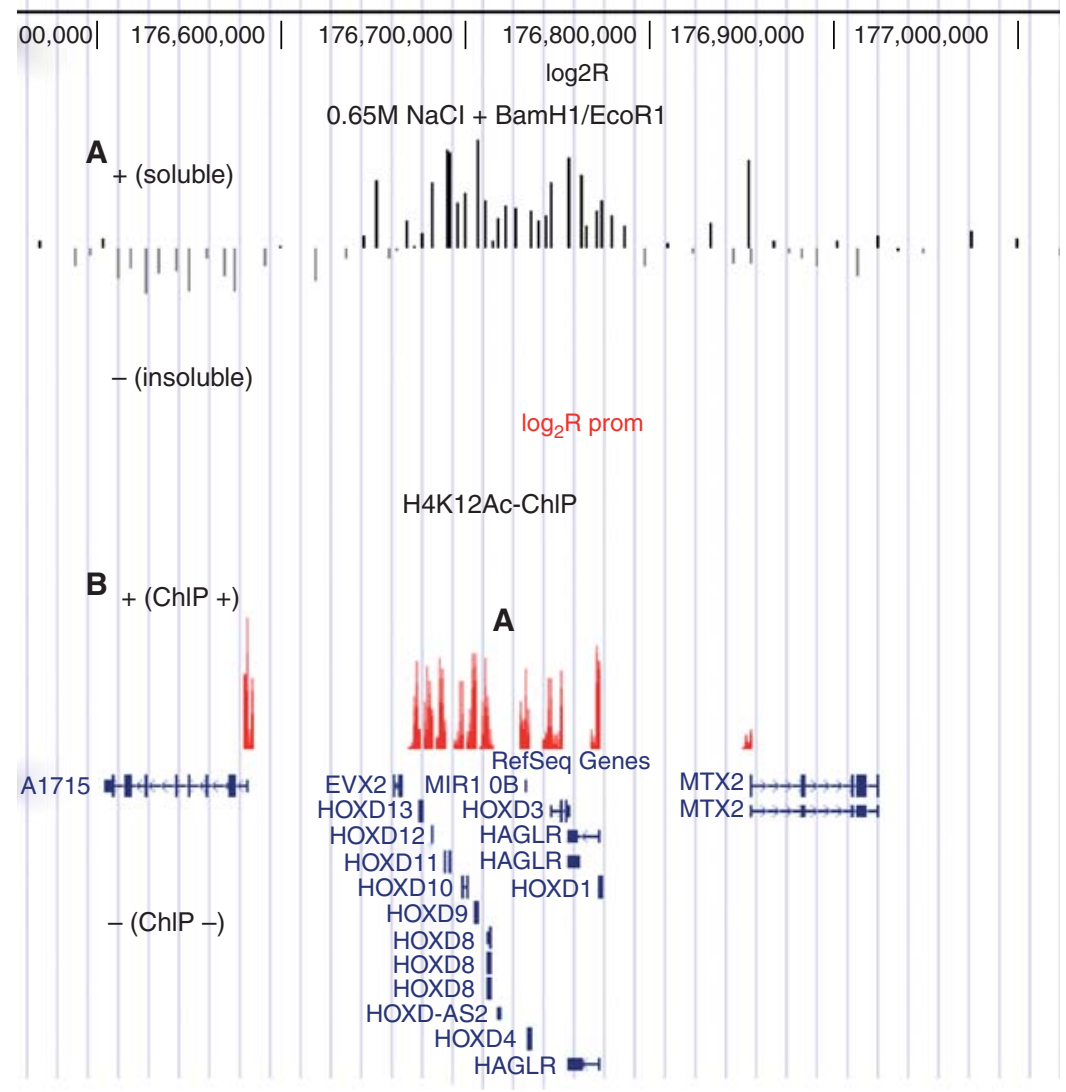

Figure 3. Properties of sperm chromatin packaging. The general consensus on sperm chromatin packaging is that regions or domains that are nucleosome enriched are also less condensed (more euchromatic) than regions that are protamine bound. An example of this is shown on the UCSC browser traces for the HOXD cluster of sperm chromatin $(A)$ extracted by low-salt $(0.65 \mathrm{M} \mathrm{NaCl})$ followed by digestion with restriction endonucleases) and $(B)$ in which chromatin enriched for H4K12Ac is pulled down by ChIP. The soluble $(+)$ and insoluble $(-)$ DNA targets generated by the former process were probed by an Agilent $244 \mathrm{~K}$ whole-genome microarray and shown as soluble/insoluble $\log _{2}$ ratios with positive $(+)$ values indicating solubility (Arpanahi et al. 2009). The H4K12Ac + ChIP DNA target was probed by a NimbleGen promoter array with + signals shown by red peaks (Arpanahi et al. 2009). Note the close correspondence between solubility (equivalent to accessibility) in $A$ with histone enrichment in $B$. The HOXD cluster can be easily accommodated within two or three protamine toroids, but these data indicate that it is unlikely to be associated with protamine.

to $50 \mathrm{kbp}$ of DNA); however, the most prosaic explanation for the data presented is that the cluster is excluded from protamine binding altogether. In general, sequencing data for nucleosome-bound DNA does not appear to support the current model for DNA packaging in the sperm in which nucleosomes are confined to providing sites of attachment to the nuclear matrix through intertoroidal links (Fig. 1) (Ward 2010). The raw sequence data from these studies is available for anyone to download and examine for themselves.

\section{SPERM RNA}

In close association with the chromatin (Wykes et al. 1997; Li et al. 2008), sperm RNA is compositionally complex and includes thousands of distinct species. For previous discussions on the subject of RNA carriage in human sperm, 
D. Miller

the reader is directed to the comprehensive reviews (Hamatani 2012; Sendler et al. 2013; Miller 2014). In this regard, qualitative aspects have been addressed by combinations of targetdirected and nontargeted PCR-based approaches including differential display (DD) (Miller 1997), serial analysis of gene expression (SAGE) (Zhao et al. 2006), microarrays (Gilbert et al. 2007; Platts et al. 2007; Bissonnette et al. 2009; Garrido et al. 2009; Lalancette et al. 2009; Bonache et al. 2012; Govindaraju et al. 2012; Das et al. 2013), and ultimately as the expense has come down, by massively parallel NGS. These techniques confirm that human sperm contain examples of all known RNA subtypes including mRNAs, lncRNAs, and sncRNAs. Zhao and colleagues (2006), for example, reported that among the most abundant (human) sperm RNAs identified by SAGE analysis are those for ribosomal proteins. A similarly complex repertoire of RNAs was recently reported in the sperm of the fruit fly (Fischer et al. 2012) with an equivalent abundance of RNAs derived from ribosomal protein complexes, suggesting the sperm RNA is compositionally conserved across divergent animal species. The wider adoption of NGS of sperm RNA has generally confirmed these earlier reports and extended them to porcine (Yang et al. 2010), equine (Das et al. 2013), and murine (Fang et al. 2014; Gapp et al. 2014) sperm.

Human sperm RNA has been shown to be clinically informative in relation to pregnancy rates (Garcia-Herrero et al. 2009; Bonache et al. 2012) and evidence for differential "expression" of some mRNAs in relation to fertility and return rates in bull sperm has also been presented using a combination of subtractive hybridization and a bespoke cDNA array (Lalancette et al. 2008; Bissonnette et al. 2009) or arrays based on human oligo probes (Gilbert et al. 2007). The recently developed Affymetrix bovine array platform was used in another report (Feugang et al. 2010). The first high-resolution RNA-sequencing report on cryopreserved bovine sperm appeared in 2013 (Card et al. 2013). The advantage of all DNA sequencing-based strategies is that they are not dependent on the presence of specific probes and so should provide more ac- curate descriptions of the identity and relative abundance of sperm RNAs as improvements are made in the content and accuracy of their annotated genomes.

A feature that the sperm RNA of all species (where reported) display is a tendency toward fragmentation (Bissonnette et al. 2009; Sendler et al. 2013; Ing et al. 2014). Bioanalyzer profiles of sperm RNA are generally lacking in $28 \mathrm{~S}$ and 18S RNA peaks that form the basis of the "all important" RNA integrity number (RIN) of RNA quality. The range of smaller RNAs recovered from sperm, coupled with the relative absence of intact large ribosomal subunit RNAs, suggests that it is fragmented either by design or possibly by the isolation process itself (see below and Cappallo-Obermann et al. 2011). To date, the former possibility has been best explored in human spermatozoa (Johnson et al. 2011b). In addition to confirming the fragmented nature of human sperm RNA, sequencing studies on human sperm have also begun to highlight the importance of the methods chosen for library construction (Sendler et al. 2013). Residual genomic DNA contamination in sperm RNA preparations is an additional problem for which a solution has still not been found (Li et al. 2008; D. Miller, unpubl.). Unlike most somatic cells, in which RNA dominates and the DNA to RNA ratio is generally $<1$, in sperm, it is $>1$ (one sperm contains $3.6 \mathrm{pg}$ of DNA compared with an estimated $30.0 \mathrm{fg}$ of RNA). Moreover, the RNA is in intimate association with the DNA (Concha et al. 1993; Wykes et al. 1997; Li et al. 2008), which makes their resolution from each other far more difficult to achieve than with somatic cells.

Armed with knowledge of these unusual characteristics of sperm RNA and its isolation and using a number of different strategies for building sperm RNA-seq libraries for NGS, Sendler et al. (2013) reported $>22,000$ distinct RNA species in human sperm, significantly more than reported previously using relatively primitive macroarrays (Ostermeier et al. 2004) (although many of these unique transcripts probably derive from the same annotated genes). Using the same (Illumina) sequencing platform, alternative strategies for building libraries were 
used to help assess their effects on sperm RNA sequence composition and complexity. Some libraries were built from polyA + enriched RNA; others were constructed from unselected (total) RNA. The twin advantages of selecting for polyA + RNA are that they focus primarily on the protein coding genome. By ignoring all other RNAs, greater sequencing depth of this compartment can be achieved. Higher depth sequencing of small noncoding RNAs can also be achieved by size fractionation of total RNA. Early experiments with total sperm RNA, however, ran into trouble with their high rRNA content, which tended to dominate sequencing reads (SA Krawetz, pers. comm.). Although missing as intact entities from bioanalyzer profiles, highly fragmented $28 \mathrm{~S}$ and $18 \mathrm{~S}$ RNAs are present in sperm RNA preparations and tend to dominate sequencing reads (even RNA that is size fractionated for small RNAs will contain fragmented $28 \mathrm{~S}$ and $18 \mathrm{~S}$ rRNAs, if the fragments are small enough). Methods aimed at reducing rRNA from total RNA preparations (RiboZero, for example) rely largely on secondary structure to recognize and remove large subunit rRNAs, and so their utility with degraded RNA sources can be unpredictable. A single primer isothermal amplification-based process (SPIA) that uses randomers designed to "ignore" ribosomal RNA sequences was used for constructing some libraries, so reducing the number of irrelevant rRNA reads in sequencing data.

Sendler and colleagues reported distinct ontological descriptions from the more abundant, intact transcripts, and detected many RNAs with alternative polyadenylation (APA) sites compared with corresponding testis RNAs (Sendler et al. 2013). These data suggest that $3^{\prime}$ truncation may be a normal consequence of APA and under active cellular control rather than a passive consequence of RNA fragmentation. These characteristics of human sperm RNA, including the presence of RNAs derived from introns in genes expressed highly in the testis but where no such (coding) transcript persists, suggest that similar characteristics may be found in the sperm RNA from other species studied to date if fresh interrogations of their respective RNA-seq databases are undertaken (Anderson et al. 2013; Card et al.
2013; Das et al. 2013; Loraine et al. 2013; Sendler et al. 2013; Fang et al. 2014).

Surveys of noncoding (nc) RNAs from the sperm of several species have also appeared, including reports on short ncRNAs. Krawetz and colleagues reported that $>65 \%$ of ncRNA in human sperm was derived from repetitive DNA sequence (primarily, long [LINE] and short [SINE], Interspersed Nuclear Elements), with piRNAs and miRNAs between them comprising another 25\% and Long Tandem Repeat (LTR) RNAs comprising $\sim 10 \%$ (Krawetz et al. 2011). These results reflect the much earlier description of abundant ALU-like RNAs in human spermatozoa detected by random sequencing of PCR amplicons (Miller 2000). Less clearly defined sncRNA classes including RNAs aligning to transcription start sites (TSS) and gene promoter sequences were described (Krawetz et al. 2011). Interestingly, the reported targets for human miRNAs and piRNAs were mainly directed toward repetitive, histone bound, and TSS/promoter sequences. A more recent report on piRNAs in the human testis concluded that their targets were a mix of repetitive and UTR sequences of selected genes (Ha et al. 2014). Although this report made use of testis piRNAs enriched specifically for sequencing by prior periodate treatment, it would be interesting to examine their overlap with the more general sperm sncRNA sequencing data. Many of the sncRNAs reported are known to be involved in either regulating mRNA expression (miRNAs) or ensuring that the expression of repetitive (mobile) elements such as the LINE and LTR retroposons is repressed (Bourc'his and Voinnet 2010; de Boer et al. 2010). Their presence in sperm is interesting and may reflect a dynamic process during spermiogenesis aimed at counteracting the temporarily weakened suppression of mobile element expression that may be a consequence of the repackaging of the paternal genome (Bourc'his and Voinnet 2010) (see last section). LTRs are also active in the early embryo where they are thought to provide alternative, transcription-activating promoters (Peaston et al. 2007).

Short ncRNAs (mainly siRNAs) have been reported in the sperm of cows (Govindaraju 
D. Miller

et al. 2012; Du et al. 2014; Tscherner et al. 2014), horse (Das et al. 2013), pig (Curry et al. 2009), mice (Liu et al. 2012), and pollen (Chambers and Shuai 2009; Grant-Downton et al. 2009). Members of the miR-34 family have been the focus in many studies as they are known to be involved in the regulation of spermatogenesis (Bouhallier et al. 2010; Liang et al. 2012) and are implicated in the suggested communication dynamics between sperm and eggs (see Liu et al. 2012; Tscherner et al. 2014 and last section). They are also among the more abundant miRNAs of human sperm (Krawetz et al. 2011). Members of the family have also been implicated in infertility (Abu-Halima et al. 2013; Comazzetto et al. 2014) and even in promoting embryonic development (Liu et al. 2012).

We shall return to the role of sperm RNA in context of paternal epigenomics in the next section. However, before finishing our consideration of the compositional complexity of sperm RNA, it is worth mentioning that reports on the clinical utility of sperm RNA have appeared recently, comparing sperm mRNA profiles using either array-PCR covering a defined batch of selected gene probes or whole genome microarrays with many thousands of unselected gene probes. Platts et al. (2007), used the Affymetrix array platform to cluster sperm RNA profiles into normozoospermic and teratozoospermic categories. They showed that the ubiquitinproteasome regulated protein recycling pathway is the most significant ontological signature discriminating these phenotypes. Garcia-Herrero et al. (2010) used the Agilent whole genome microarray platform to identify differences in the sperm RNA profiles between couples achieving or not achieving pregnancy by intrauterine insemination (IUI). A bespoke array-PCRbased approach was used to distinguish between the sperm RNA profiles of fertile versus infertile men with no discernable differences in their respective semen profiles as characterized by the World Health Organization (W.H.O. 1999; Garrido et al. 2009). A similar study on 68 patients reported reproducible differences in the sperm RNA levels from 87 target genes from normozoospermic donors (Bonache et al. 2012). These studies suggest that molecular anomalies can give rise to forms of infertility that cannot always be detected or distinguished by a standard microscopic semen analysis. Similar studies have been reported for other economically important species, showing that sperm RNA is becoming an important tool in fertility assessment (Lalancette et al. 2008; Feugang et al. 2010; Card et al. 2013; Das et al. 2013; Ing et al. 2014).

\section{THE INCOMING SPERM'S IMPACT ON THE OOCYTE}

In addition to their regulatory roles in spermatogenesis, sperm miRNAs and piRNAs may perform some function related to the unusual activity of long terminal repeat retroposons in the early embryo or to some other paternally derived regulatory activity. As indicated in the first section, the existence of gynogenotes using just maternally derived gametes suggests that a paternal epigenetic contribution is either not required for "normal" development or can be mimicked (Kono et al. 2004). However, a sperm's "acceptance" by the egg may still be subject to "checks" that ensure its compatibility and RNAs delivered by the sperm may help to facilitate this process (Miller et al. 2010; Jodar et al. 2013). In this regard, one might expect dysfunctions of a checking mechanism to manifest as either a failure of fertilization or a failure of successful activation of the embryonic genome. The proportion of eggs that are successfully fertilized (two pronuclei visible) following IVF is normally quite high $(>70 \%)$; clinical pregnancy rates, however, are considerably lower ( $\sim 35 \%)$ and just 5\% of all aspirated eggs will go to term (Ferraretti et al. 2013).

Although the delivered paternal and receiving maternal genomes are of equivalent mass (and, hence, contribution), the quantity of RNA delivered by the sperm is minute compared with the RNA reservoir in the recipient egg. Despite this "imbalance," the likelihood that sperm RNAs can alter zygotic phenotype has been greatly enhanced by reports of sperm RNA-mediated epigenetic effects in the mouse (Rassoulzadegan et al. 2006; Gapp et al. 2014). The former reported a $c$ Kit mediated paramu- 
tation effect on coat color and the latter, a transgenerational behavioral effect, with both reports concluding that the signals mediating these effects were epigenetic and derived from the fertilizing sperm. An additional study showing a large-offspring effect using oocyte microinjection of a particular miRNA (miR-124) targeting the Sox 9 gene promoter has also been reported (Grandjean et al. 2009). These reports suggest that the MII oocyte is highly sensitive to RNA ingress that can affect offspring phenotype. In this regard, one particular miRNA (miR-34c), involved in p53 regulation and thought to be important in promoting the postmeiotic events driving spermiogenesis (Bouhallier et al. 2010; Liang et al. 2012) is also present in relatively high abundance in both mature human (Jodar et al. 2013) and mouse (Liu et al. 2012) sperm. Evidence for the involvement of this miRNA in embryonic genome activation in the mouse has been obtained recently by selective miR-34c knock-down in recipient occytes (Liu et al. 2012).

These sperm RNA-mediated epigenetic effects offer plausible solutions for the mechanism driving trans-generational inheritance of acquired characteristics (TAC), first described in human cohorts with the Swedish Överkalix population. The Avon Longitudinal Study of Parents and Children (ALSPAC) is among the best studied (Pembrey et al. 2006; Northstone et al. 2014). Animal models have been used to focus on TAC effects following fetal exposure to cytotoxic agents. Anway and Skinner (Anway et al. 2005) reported such an effect (impaired spermatogenesis) in up to the F4 generation in males derived from F0 females exposed to the fungicide vinclozolin. The more recent reports in the mouse (Dias and Ressler 2014; Gapp et al. 2014) have essentially brought sperm (RNA) back into focus as a likely vehicle for trans-generational epigenetic inheritance (Rodgers et al. 2013).

Paramutation, which does not change the DNA sequence of the target gene, resembles the proposed mechanism driving sperm-mediated gene (SMGT) and reverse gene transfer (SMRGT). These processes involve incubating sperm with high levels of a transfecting DNA (or
RNA) that is then delivered to the egg at fertilization and can affect offspring phenotype accordingly but without altering genotype. SMGT and SMRGT, as reviewed by Smith and Spadafora (2005) and more recently by Sciamanna et al. (2009), involves the processing of the transforming sequence as an extra-nuclear episomal element that rarely (but occasionally) integrates into the genome. As the process relies on incubating sperm beforehand with the transforming construct, the phenomena suggest that spermatozoa have an innate ability to absorb and process nucleic acids. Absorbed DNA is thought to be processed through an RNA intermediate that leads to a heritable episomal cDNA presence (Sciamanna et al. 2003). The unexpected presence of DNA and RNA dependent polymerase activities in mature murine sperm was originally described in mature human spermatozoa and semen back in the 1970s (Witkin and Bendich 1977). It is the activity of an operational reverse transcriptase in mature spermatozoa that is thought to be an essential component of the SMGT/SMRGT (henceforth referred to as simply SMRGT) mechanism (Sciamanna et al. 2003, 2009).

The more dramatic DNA fragmentation response could ensure that foreign DNA absorbed en route to the oocyte cannot reach the egg (Sotolongo et al. 2003; Ward and Ward 2004), but how then to accommodate SMRGT and what natural biological process might it serve? The proposed mechanism for SMRGT suggests that under the "right" circumstances the sperm's nuclear transcriptional machinery can be "reactivated" sufficiently for RNA transcription to take place (Sciamanna et al. 2009). This is hard to reconcile with the available evidence showing that sperm are transcriptionally silent (Premkumar and Bhargava 1972; Grunewald et al. 2005). It is possible, however, that some sperm incubation conditions permit windows of transcriptional activity; sperm capacitation, for example, is a highly dynamic process in which considerable remodeling of the sperm plasmalemma takes place and is also thought to be associated with translational activity (Gur and Breitbart 2008; Zhao et al. 2009). Transcriptional activity of exogenously derived DNA will require the oc- 
D. Miller

currence of rare integration events that could be accommodated within the less densely packaged, nucleosomal regions of sperm chromatin. They might even be expected to occur more frequently in regions enriched in nucleosomes carrying H3K27me3 or H4K27Ac modified histones (both marks of more open, transcriptionally active chromatin in somatic cells) and where transcription factors would have easier access (Miller et al. 2010; Brunner et al. 2014; Gannon et al. 2014).

The extreme rarity of full integration events was originally put forward to explain why they are so difficult to find in SGRMT transfected tissues (Sciamanna et al. 2009). Current thinking is that, although full DNA integration in sperm (or any other cell type for that matter) is very rare, propagation of the resulting episomal cDNAs behaving rather like independent retrogenes is the key to the phenotypes they confer on sperm-mediated transgenic animals (Sciamanna et al. 2009). It is the concept of SMRGT as a retrogene-like process that is particularly interesting given the evidence for an active reverse-transcriptase activity in sperm and semen. Similar observations have been reported in oocytes and early embryos (Evsikov et al. 2004; Peaston et al. 2007), although these were based on RNA identities rather than activity. Reproductive tracts and tissues are often rich sources of retroposon activity. Murine epididimides and seminal fluid, for example, harbor large numbers of (TEM-imaged) proviral particles, which are derived from endogenous LTR containing retrotransposons (Kiessling 1989). These are particles can also be found in oocytes (Nilsson et al. 1981) and early fetal tissues (Mondal and Hofschneider 1982). If retroposons are the source of active RT enzyme in spermatozoa and oocytes (Beraldi et al. 2006), their expression must be a special property of germ cells, because in all normal somatic cells retroposon expression is almost completely repressed by extensive DNA methylation (Bender 2012; Carrell 2012).

Sperm RNA and DNA/RNA retrogenically mediated SMRGT may be the keys to understanding non-Mendelian trans-generational inheritance, but they may also provide an insight into sperm-egg interactions that helps ensure genomic security and possibly even the acceptance of the incoming sperm. The oocyte is the only cell designed to accept another cell as a prelude to syngamy. Considering the risk to genomic security posed by the invasion of a "foreign," albeit highly selected (under natural conditions), cell, carrying with it potentially retrogenically active elements, it is highly unlikely that a surveillance mechanism has not evolved to check the sperm's compatibility and ensure that it is not introducing deleterious "selfish" elements such as retroposons. This is akin to the concept of "confrontation and consolidation" described by Bourc'his and Voinnet (2010) as a solution to potentially hazardous retroposon activation during nonmammalian gametogenesis, to which the concept of recognition and acceptance can be added in relation to the incoming mammalian sperm. By the same token, the mechanisms protecting genomes from deleterious external intrusions may also have helped to shape them over evolutionary time and have become finally tuned to accommodate potentially helpful adaptive changes (de Boer et al. 2010).

The key features of the confrontation, consolidation (recognition and acceptance) hypothesis are that the incoming sperm must be both cytoplasmically and genetically compatible with the egg before development can occur (Fig. 2). Cytoplasmic compatibility is likely checked through interactions between sperm and oocyte RNAs using mechanisms analogous to the confrontation pathways ensuring gamete compatibility in flies, flowering plants, and ciliates (Bourc'his and Voinnet 2010). It is certainly the case that murine eggs contain high levels of retroposon RNA and that sperm contain both piRNAs and miRNAs that could potentially recognize motifs on these retrogenic RNAs leading to their eventual silencing and/or degradation. Conversely, oocyte piRNAs and miRNAs, originally tasked to neutralizing retroposons introduced by the sperm, could have become coopted into recognition pathways that check the incoming sperm for compatibility. An intriguing possibility, in this regard, is that the check might require a reverse-transcription mediated 
cDNA synthesis step that makes use of both an egg and a sperm-derived RNA template, generating an episomal recognition cDNA that provides an acceptance "passport" for the incoming sperm. Such a passport would not be required by gynegenetic parthenotes in which a confrontational event does not take place.

This hypothesis is not as far-fetched as it may sound. Evidence for the existence of such an RT-dependent mechanism has been reported in which the enzyme's activity was blocked with antiretroviral agents. Treated murine zygotes showed irreversible developmental arrest at the two to four cell stages, coincident with the timing of murine embryonic genome activation (ZGA) (Pittoggi et al. 2003). Embryo implantation in mice could also be blocked with antisense morpholinos specifically targeting the LINE 1 ORF2, which encodes a functioning RT enzyme (Beraldi et al. 2006). It is known, through the expression of $\mathrm{p} 40$ ribonucleoprotein encoded by LINE 1's ORF 1, that these elements are expressed in the testis (Branciforte and Martin 1992) and their occasional and pathological insertion into and inactivation of essential genes is occasionally observed (Kazazian et al. 1988; Sironen et al. 2007). LINE 1 -mediated exon shuffling is a potentially powerful force for reshaping the genome (Moran et al. 1999; Ade et al. 2013; Alzohairy et al. 2013; Belan 2013) and, as indicated above (see the preceding section), it may provide alternative promoter sites for oocyte-expressed genes (Peaston et al. 2004, 2007) as well as confrontational "negotiation" between the incoming sperm and recipient egg.

The unusual packaging of sperm chromatin, which, when it enters the egg, is in a chromatin scaffold containing both protamine toroids and nucleosomes can also be considered in relation to a confrontation and consolidation mechanism. In this regard, the incoming sperm would be faced by a compatibility check that is facilitated by either its differentially packaged chromatin and/or its complex lexicon of histone modifications. Interestingly, the nucleosomal compartment (or at least a fraction of it) is thought to be enriched in retroposon sequences (Pittoggi et al. 1999; Carone et al. 2014; Samans et al. 2014). Nucleosome-based regions of the paternal genome are likely to be among the first accessed by maternal remodeling factors, potentially leaving these exposed retroposons available for hazardous expression. To prevent this from occurring, as in Drosophila, maternal piRNAs may recognize and interact with these retroposon sequences, marking them for rapid condensation into heterochromatin (Bourc'his and Voinnet 2010). This in itself can act as a useful "co-opted" recognition system because a mismatch could lead to the massive overexpression of retroposons and subsequent infertility (as observed in interspecies hybrids). However, the nonrandom presence of genic sequences in the nuclease-accessible compartment, where most of the histone modifications are thought to lie, could also play roles in the "acceptance" level of the model. Here, maternal factors (which may include sncRNAs and lncRNAs) could scan the paternal genome for compatibility using specific histone modifications that mark regions containing embryologically expressed genes in the correct context (Arpanahi et al. 2009; Hammoud et al. 2009). Again, closely related species may be able to accommodate these checks as far as developmental competence is concerned, but, depending on the evolutionary distance between them, their hybrid offspring would be mostly infertile (Maheshwari and Barbash 2011).

\section{CONCLUSIONS}

Evidence to date shows that the sperm delivers a far more complex package to the ooplasm than might be considered necessary. One plausible explanation is that from the oocyte's perspective, the sperm is an invasive and potentially harmful object that requires checking before it can be accepted for syngamy and that a combination of the RNA content and differential packaging of the genome facilitates this process. Many failures of fertilization or developmental failure (through both natural and assisted conception) could be attributed to the sperm being unable to pass the checks necessary for successful syngamy and embryonic genome activation. It follows, therefore, that selection 
D. Miller

of sperm for intracytoplasmic sperm injection (ICSI) is probably far more important than we have traditionally thought.

The more dynamic nature of the sperm nucleus suggested by the uptake and integration of exogenous RNA/DNA may be a preparatory component or a product of the gamete checking mechanism. If the former, then the question arises as to whether any endogenous sperm RNA can also be so processed. If this does occur on a regular basis (perhaps during sperm capacitation), then one might expect more cDNA copies of retro-transcribed RNAs in sperm compared with somatic nuclei. These could be revealed by deep DNA sequencing. Moreover, a more dynamic sperm nucleus that can potentially transform the recipient egg with new genetic information (the basis of SMRGT and possibly sperm-mediated trans-generational inheritance) also supports the notion that interactions between gametes and exogenously derived nucleic acids are at the heart of heritable changes that appear to bypass normal Mendelian modes of inheritance. The importance of reverse transcriptase in this regard should not be overlooked as, alongside retroposon (and transposon)-mediated genomic changes, it has had probably the greatest effect on genomic plasticity and the rapid generation of new phenotypes and ultimately genotypes.

\section{REFERENCES}

Abu-Amero S, Monk D, Apostolidou S, Stanier P, Moore G. 2006. Imprinted genes and their role in human fetal growth. Cytogenet Genome Res 113: 262-270.

Abu-Halima M, Hammadeh M, Schmitt J, Leidinger P, Keller A, Meese E, Backes C. 2013. Altered microRNA expression profiles of human spermatozoa in patients with different spermatogenic impairments. Fertil Steril 99: 1249-1255.e1216.

Ade C, Roy-Engel AM, Deininger PL. 2013. Alu elements: An intrinsic source of human genome instability. Curr Opin Virol 3: 639-645.

Alzohairy AM, Gyulai G, Jansen RK, Bahieldin A. 2013. Transposable elements domesticated and neofunctionalized by eukaryotic genomes. Plasmid 69: 1-15.

Anderson SN, Johnson CS, Jones DS, Conrad LJ, Gou X, Russell SD, Sundaresan V. 2013. Transcriptomes of isolated Oryza sativa gametes characterized by deep sequencing: Evidence for distinct sex-dependent chromatin and epigenetic states before fertilization. Plant J 76: 729-741.
Anway MD, Cupp AS, Uzumcu M, Skinner MK. 2005. Epigenetic transgenerational actions of endocrine disruptors and male fertility. Science 308: 1466-1469.

Aoki F, Worrad DM, Schultz RM. 1997. Regulation of transcriptional activity during the first and second cell cycles in the preimplantation mouse embryo. Dev Biol 181: 296-307.

Arpanahi A, Brinkworth M, Iles D, Krawetz SA, Paradowska A, Platts AE, Saida M, Steger K, Tedder P, Miller D. 2009. Endonuclease-sensitive regions of human spermatozoal chromatin are highly enriched in promoter and CTCF binding sequences. Genome Res 19: 1338-1349.

Aul RB, Oko RJ. 2002. The major subacrosomal occupant of bull spermatozoa is a novel histone $\mathrm{H} 2 \mathrm{~B}$ variant associated with the forming acrosome during spermiogenesis. Dev Biol 242: 376-387.

Belan E. 2013. LINEs of evidence: Noncanonical DNA replication as an epigenetic determinant. Biol Direct 8: 22.

Bell O, Tiwari VK, Thoma NH, Schubeler D. 2011. Determinants and dynamics of genome accessibility. Nat Rev Genet 12: 554-564.

Bender J. 2012. RNA-directed DNA methylation: Getting a grip on mechanism. Curr Biol 22: R400-R401.

Beraldi R, Pittoggi C, Sciamanna I, Mattei E, Spadafora C. 2006. Expression of LINE-1 retroposons is essential for murine preimplantation development. Mol Reprod Dev 73: $279-287$.

Bissonnette N, Levesque-Sergerie JP, Thibault C, Boissonneault G. 2009. Spermatozoal transcriptome profiling for bull sperm motility: A potential tool to evaluate semen quality. Reproduction 138: 65-80.

Bjorndahl L, Kvist U. 2014. Structure of chromatin in spermatozoa. Adv Exp Med Biol 791: 1-11.

Bonache S, Mata A, Ramos MD, Bassas L, Larriba S. 2012. Sperm gene expression profile is related to pregnancy rate after insemination and is predictive of low fecundity in normozoospermic men. Hum Reprod 27: 1556-1567.

Bouhallier F, Allioli N, Lavial F, Chalmel F, Perrard MH, Durand P, Samarut J, Pain B, Rouault JP. 2010. Role of miR-34c microRNA in the late steps of spermatogenesis. RNA 16: 720-731.

Bourc'his D, Voinnet O. 2010. A small-RNA perspective on gametogenesis, fertilization, and early zygotic development. Science 330: 617-622.

Branciforte D, Martin SL. 1992. Expression of line-1 RNA and protein in mouse testis. Mol Biol Cell 3: A101.

Brunner AM, Nanni P, Mansuy IM. 2014. Epigenetic marking of sperm by post-translational modification of histones and protamines. Epigenetics Chromatin 7: 2.

Brykczynska U, Hisano M, Erkek S, Ramos L, Oakeley EJ, Roloff TC, Beisel C, Schübeler D, Stadler MB, Peters AH. 2010. Repressive and active histone methylation mark distinct promoters in human and mouse spermatozoa. Nat Struct Mol Biol 17: 679-687.

Buric M, Hulak M, Kouba A, Petrusek A, Kozak P. 2011. A successful crayfish invader is capable of facultative parthenogenesis: A novel reproductive mode in decapod crustaceans. PLoS ONE 6: e20281.

Cappabianca L, Thomassin H, Pictet R, Grange T. 1999. Genomic footprinting using nucleases. Methods $\mathrm{Mol}$ Biol 119: 427-442. 
Cappallo-Obermann H, Schulze W, Jastrow H, Baukloh V, Spiess AN. 2011. Highly purified spermatozoal RNA obtained by a novel method indicates an unusual 28S/ $18 \mathrm{~S}$ rRNA ratio and suggests impaired ribosome assembly. Mol Hum Reprod 17: 669-678.

Card CJ, Anderson EJ, Zamberlan S, Krieger KE, Kaproth M Sartini BL. 2013. Cryopreserved bovine spermatozoal transcript profile as revealed by high-throughput ribonucleic acid sequencing. Biol Reprod 88: 49.

Carone BR, Hung JH, Hainer SJ, Chou MT, Carone DM, Weng Z, Fazzio TG, Rando OJ. 2014. High-resolution mapping of chromatin packaging in mouse embryonic stem cells and sperm. Dev Cell 30: 11-22.

Carrell DT. 2012. Epigenetics of the male gamete. Fertil Steril 97: 267-274.

Casas E, Vavouri T. 2014. Sperm epigenomics: Challenges and opportunities. Front Genet 5: 330.

Castillo J, Amaral A, Azpiazu R, Vavouri T, Estanyol JM, Ballescà JL, Oliva R. 2014. Genomic and proteomic dissection and characterization of the human sperm chromatin. Mol Hum Reprod 20: 1041-1053.

Chambers C, Shuai B. 2009. Profiling microRNA expression in Arabidopsis pollen using microRNA array and realtime PCR. BMC Plant Biol 9: 87.

Chen Z, Liu Z, Huang J, Amano T, Li C, Cao S, Wu C, Liu B, Zhou L, Carter MG, et al. 2009. Birth of parthenote mice directly from parthenogenetic embryonic stem cells. Stem Cells 27: 2136-2145.

Comazzetto S, Di Giacomo M, Rasmussen KD, Much C, Azzi C, Perlas E, Morgan M, O'Carroll D. 2014. Oligoasthenoteratozoospermia and infertility in mice deficient for miR-34b/c and miR-449 loci. PLoS Genet 10: e1004597.

Concha II, Urzua U, Yanez A, Schroeder R, Pessot C, Burzio LO. 1993. U1 and U2 snRNA are localized in the sperm nucleus. Exp Cell Res 204: 378-381.

Curry E, Ellis SE, Pratt SL. 2009. Detection of porcine sperm microRNAs using a heterologous microRNA microarray and reverse transcriptase polymerase chain reaction. Mol Reprod Dev 76: 218-219.

Das PJ, McCarthy F, Vishnoi M, Paria N, Gresham C, Li G, Kachroo P, Sudderth AK, Teague K, Love CC, et al. 2013. Stallion sperm transcriptome comprises functionally coherent coding and regulatory RNAs as revealed by microarray analysis and RNA-seq. PLoS ONE 8: e56535.

de Boer P, Ramos L, de Vries M, Gochhait S. 2010. Memoirs of an insult: Sperm as a possible source of transgenerational epimutations and genetic instability. Mol Hum Reprod 16: 48-56.

Dias BG, Ressler KJ. 2014. Parental olfactory experience influences behavior and neural structure in subsequent generations. Nat Neurosci 17: 89-96.

Du Y, Wang X, Wang B, Chen W, He R, Zhang L, Xing X, Su J, Wang Y, Zhang Y. 2014. Deep sequencing analysis of microRNAs in bovine sperm. Mol Reprod Dev 81: 1042 1052.

Eirin-Lopez JM, Ausio J. 2009. Origin and evolution of chromosomal sperm proteins. BioEssays 31: 1062-1070.

Erkek S, Hisano M, Liang CY, Gill M, Murr R, Dieker J, Schübeler D, van der Vlag J, Stadler MB, Peters AH. 2013. Molecular determinants of nucleosome retention at CpG-rich sequences in mouse spermatozoa. Nat Struct Mol Biol 20: 868-875.

Evsikov AV, de Vries WN, Peaston AE, Radford EE, Fancher KS, Chen FH, Blake JA, Bult CJ, Latham KE, Solter D, et al. 2004. Systems biology of the 2-cell mouse embryo. Cytogenet Genome Res 105: 240-250.

Fang P, Zeng P, Wang Z, Liu M, Xu W, Dai J, Zhao X, Zhang D, Liang D, Chen X, et al. 2014. Estimated diversity of messenger RNAs in each murine spermatozoa and their potential function during early zygotic development. Biol Reprod 90: 94.

Ferraretti AP, Goossens V, Kupka M, Bhattacharya S, de Mouzon J, Castilla JA, Erb K, Korsak V, Nyboe Andersen A, European IVF-Monitoring (EIM) Consortium for the European Society of Human Reproduction and Embryology (ESHRE). 2013. Assisted reproductive technology in Europe, 2009: Results generated from European registers by ESHRE. Hum Reprod 28: 2318-2331.

Feugang JM, Rodriguez-Osorio N, Kaya A, Wang H, Page G, Ostermeier GC, Topper EK, Memili E. 2010. Transcriptome analysis of bull spermatozoa: Implications for male fertility. Reprod Biomed Online 21: 312-324.

Fischer BE, Wasbrough E, Meadows LA, Randlet O, Dorus S, Karr TL, Russell S. 2012. Conserved properties of Drosophila and human spermatozoal mRNA repertoires. Proc Biol Sci 279: 2636-2644.

Fuentes-Mascorro G, Serrano H, Rosado A. 2000. Sperm chromatin. Arch Androl 45: 215-225.

Fujita MK, Moritz C. 2009. Origin and evolution of parthenogenetic genomes in lizards: Current state and future directions. Cytogenet Genome Res 127: 261-272.

Gannon JR, Emery BR, Jenkins TG, Carrell DT. 2014. The sperm epigenome: Implications for the embryo. $A d v$ Exp Med Biol 791: 53-66.

Gapp K, Jawaid A, Sarkies P, Bohacek J, Pelczar P, Prados J, Farinelli L, Miska E, Mansuy IM. 2014. Implication of sperm RNAs in transgenerational inheritance of the effects of early trauma in mice. Nat Neurosci 17: 667-669.

Garcia-Herrero S, Meseguer M, Martinez-Conejero JA, Remohi J, Pellicer A, Garrido N. 2009. The transcriptome of spermatozoa used in homologous intrauterine insemination varies considerably between samples that achieve pregnancy and those that do not. Fertil Steril 94: 13601373.

Garcia-Herrero S, Garrido N, Martinez-Conejero JA, Remohi J, Pellicer A, Meseguer M. 2010. Differential transcriptomic profile in spermatozoa achieving pregnancy or not via ICSI. Reprod Biomed Online 22: 25-36.

Garrido N, Martínez-Conejero JA, Jauregui J, Horcajadas JA, Simón C, Remohí J, Meseguer M. 2009. Microarray analysis in sperm from fertile and infertile men without basic sperm analysis abnormalities reveals a significantly different transcriptome. Fertil Steril 91: 1307-1310.

Gatewood JM, Cook GR, Balhorn R, Bradbury EM, Schmid CW. 1987. Sequence-specific packaging of DNA in human sperm chromatin. Science 236: 962-964.

Gatewood JM, Cook GR, Balhorn R, Schmid CW, Bradbury EM. 1990. Isolation of 4 core histones from human sperm chromatin representing a minor subset of somatic histones. J Biol Chem 265: 20662-20666. 
D. Miller

Gilbert I, Bissonnette N, Boissonneault G, Vallee M, Robert C. 2007. A molecular analysis of the population of mRNA in bovine spermatozoa. Reproduction 133: 1073-1086.

Govin J, Escoffier E, Rousseaux S, Kuhn L, Ferro M, Thévenon J, Catena R, Davidson I, Garin J, Khochbin S, et al. 2007. Pericentric heterochromatin reprogramming by new histone variants during mouse spermiogenesis. $J$ Cell Biol 176: 283-294.

Govindaraju A, Uzun A, Robertson L, Atli MO, Kaya A, Topper E, Crate EA, Padbury J, Perkins A, Memili E. 2012. Dynamics of microRNAs in bull spermatozoa. Reprod Biol Endocrinol 10: 82.

Grandjean V, Gounon P, Wagner N, Martin L, Wagner KD, Bernex F, Cuzin F, Rassoulzadegan M. 2009. The miR124-Sox9 paramutation: RNA-mediated epigenetic control of embryonic and adult growth. Development 136: 3647-3655.

Grant-Downton R, Le Trionnaire G, Schmid R, RodriguezEnriquez J, Hafidh S, Mehdi S, Twell D, Dickinson H. 2009. MicroRNA and tasiRNA diversity in mature pollen of Arabidopsis thaliana. BMC Genomics 10: 643.

Grunewald S, Paasch U, Glander HJ, Anderegg U. 2005. Mature human spermatozoa do not transcribe novel RNA. Andrologia 37: 69-71.

Gur Y, Breitbart H. 2008. Protein synthesis in sperm: Dialog between mitochondria and cytoplasm. Mol Cell Endocrinol 282: 45-55.

Ha H, Song J, Wang S, Kapusta A, Feschotte C, Chen KC, Xing J. 2014. A comprehensive analysis of piRNAs from adult human testis and their relationship with genes and mobile elements. BMC Genomics 15: 545.

Hamatani T. 2012. Human spermatozoal RNAs. Fertil Steril 97: $275-281$.

Hammoud SS, Nix DA, Zhang H, Purwar J, Carrell DT, Cairns BR. 2009. Distinctive chromatin in human sperm packages genes for embryo development. Nature 460: 473-478.

Henikoff S, Henikoff JG, Sakai A, Loeb GB, Ahmad K. 2009. Genome-wide profiling of salt fractions maps physical properties of chromatin. Genome Res 19: 460-469.

Ihara M, Meyer-Ficca ML, Leu NA, Rao S, Li F, Gregory BD, Zalenskaya IA, Schultz RM, Mehyer RG. 2014. Paternal poly (ADP-ribose) metabolism modulates retention of inheritable sperm histones and early embryonic gene expression. PLoS Genet 10: e1004317.

Ing NH, Forrest DW, Love CC, Varner DD. 2014. Dense spermatozoa in stallion ejaculates contain lower concentrations of mRNAs encoding the sperm specific calcium channel 1 , ornithine decarboxylase antizyme 3 , aromatase, and estrogen receptor $\alpha$ than less dense spermatozoa. Theriogenology 82: 347-353.

Jenkins TG, Carrell DT. 2012. The sperm epigenome and potential implications for the developing embryo. Reproduction 143: 727-734.

Jodar M, Selvaraju S, Sendler E, Diamond MP, Krawetz SA; Reproductive Medicine Network. 2013. The presence, role and clinical use of spermatozoal RNAs. Hum Reprod Update 19: 604-624.

Johnson GD, Lalancette C, Linnemann AK, Leduc F, Boissonneault G, Krawetz SA. 2011a. The sperm nucleus:
Chromatin, RNA, and the nuclear matrix. Reproduction 141: $21-36$.

Johnson GD, Sendler E, Lalancette C, Hauser R, Diamond MP, Krawetz SA. 2011b. Cleavage of rRNA ensures translational cessation in sperm at fertilization. Mol Hum Reprod 17: 721-726.

Jurkowska RZ, Jeltsch A. 2013. Genomic imprinting-the struggle of the genders at the molecular level. Angewandte Chemie 52: 13524-13536.

Kasinsky HE, Eirin-Lopez JM, Ausio J. 2011. Protamines: Structural complexity, evolution and chromatin patterning. Protein Pept Lett 18: 755-771.

Kazazian H JR, Wong C, Youssoufian H, Scott AF, Phillips DG, Antonarakis S. 1988. Haemophilia A resulting from de novo insertion of L1 sequences represents a novel mechanism for mutation in man. Nature 332: 164-166.

Kiessling AA. 1989. Retroviruses and reproduction. Fertil Steril 51: 756-758.

Kono T, Obata Y, Wu Q, Niwa K, Ono Y, Yamamoto Y, Park ES, Seo JS, Ogawa H. 2004. Birth of parthenogenetic mice that can develop to adulthood. Nature 428: 860-864.

Krawetz SA, Kruger A, Lalancette C, Tagett R, Anton E, Draghici S, Diamond MP. 2011. A survey of small RNAs in human sperm. Hum Reprod 26: 3401-3412.

Lalancette C, Thibault C, Bachand I, Caron N, Bissonnette N. 2008. Transcriptome analysis of bull semen with extreme nonreturn rate: Use of suppression-subtractive hybridization to identify functional markers for fertility. Biol Reprod 78: 618-635.

Lalancette C, Platts AE, Johnson GD, Emery BR, Carrell DT, Krawetz SA. 2009. Identification of human sperm transcripts as candidate markers of male fertility. J Mol Med 87: 735-748.

Li Y, Lalancette C, Miller D, Krawetz SA. 2008. Characterization of nucleohistone and nucleoprotamine components in the mature human sperm nucleus. Asian J Androl 10: $535-541$

Liang X, Zhou D, Wei C, Luo H, Liu J, Fu R, Cui S. 2012. MicroRNA-34c enhances murine male germ cell apoptosis through targeting ATF1. PloS One 7: e33861.

Liu WM, Pang RT, Chiu PC, Wong BP, Lao K, Lee KF, Yeung WS. 2012. Sperm-borne microRNA-34c is required for the first cleavage division in mouse. Proc Natl Acad Sci 109: $490-494$.

Loppin B, Bonnefoy E, Anselme C, Laurencon A, Karr TL, Couble P. 2005. The histone H3.3 chaperone HIRA is essential for chromatin assembly in the male pronucleus. Nature 437: 1386-1390.

Loraine AE, McCormick S, Estrada A, Patel K, Qin P. 2013. RNA-seq of Arabidopsis pollen uncovers novel transcription and alternative splicing. Plant Physiol 162: 10921109 .

Maheshwari S, Barbash DA. 2011. The genetics of hybrid incompatibilities. Annu Rev Genet 45: 331-355.

McLay DW, Clarke HJ. 2003. Remodelling the paternal chromatin at fertilization in mammals. Reproduction 125: 625-633.

Miller D. 1997. RNA in the ejaculate spermatozoon: A window into molecular events in spermatogenesis and a record of the unusual requirements of haploid gene expres- 
sion and post-meiotic equilibration. Mol Hum Reprod 3: 669-676.

Miller D. 2000. Analysis and significance of messenger RNA in human ejaculated spermatozoa. Mol Reprod Dev 56: $259-264$.

Miller D. 2014. Sperm RNA as a mediator of genomic plasticity. Adv Biol 2014. doi: 10.1155/2014/179701.

Miller D, Brinkworth M, Iles D. 2010. Paternal DNA packaging in spermatozoa: More than the sum of its parts? DNA, histones, protamines and epigenetics. Reproduction 139: 287-301.

Mondal H, Hofschneider PH. 1982. Isolation and characterization of retrovirus-like elements from normal human fetuses. Int J Cancer 30: 281-287.

Moore T. 2012. Review: Parent-offspring conflict and the control of placental function. Placenta 33: S33-S36.

Moran JV, DeBerardinis RJ, Kazazian HH Jr. 1999. Exon shuffling by L1 retrotransposition. Science 283: 1530 1534.

Mudrak O, Chandra R, Jones E, Godfrey E, Zalensky A. 2009. Reorganisation of human sperm nuclear architecture during formation of pronuclei in a model system. Reprod Fertil Dev 21: 665-671.

Nilsson BO, Larsson E, Sundstrom P, Widehn S. 1981. Electron-microscopy of particles similar to type-C virus in human oocytes. Ups J Med Sci 86: 225-232.

Northstone K, Golding J, Davey Smith G, Miller LL, Pembrey M. 2014. Prepubertal start of father's smoking and increased body fat in his sons: Further characterisation of paternal transgenerational responses. Eur J Hum Genet 22: 1382-1386.

Oko R, Maravei D. 1994. Protein composition of the perinuclear theca of bull spermatozoa. Biol Reprod 50: 10001014.

Oliva R, Ballesca JL. 2012. Altered histone retention and epigenetic modifications in the sperm of infertile men. Asian J Androl 14: 239-240.

Ostermeier GC, Miller D, Huntriss JD, Diamond MP, Krawetz SA. 2004. Reproductive biology: Delivering spermatozoan RNA to the oocyte. Nature 429: 154.

Palmer DK, O’Day K, Margolis RL. 1990. The centromere specific histone CENP-A is selectively retained in discrete foci in mammalian sperm nuclei. Chromosoma 100: $32-36$.

Peaston AE, Evsikov AV, Graber JH, de Vries WN, Holbrook AE, Solter D, Knowles BB. 2004. Retrotransposons regulate host genes in mouse oocytes and preimplantation embryos. Dev Cell 7: 597-606.

Peaston AE, Knowles BB, Hutchison KW. 2007. Genome plasticity in the mouse oocyte and early embryo. Biochem Soc Trans 35: 618-622.

Pembrey ME, Bygren LO, Kaati G, Edvinsson S, Northstone K, Sjöström M, Golding J; ALSPAC Study Team. 2006. Sex-specific, male-line transgenerational responses in humans. Eur J Hum Genet 14: 159-166.

Pittoggi C, Renzi L, Zaccagnini G, Cimini D, Degrassi F Giordano R, Magnano AR, Lorenzini R, Lavia P. 1999. A fraction of mouse sperm chromatin is organized in nucleosomal hypersensitive domains enriched in retroposon DNA. J Cell Sci 112: 3537-3548.
Pittoggi C, Sciamanna I, Mattei E, Beraldi R, Lobascio AM Mai A, Quaglia MG, Lorenzini R, Spadafora C. 2003. Role of endogenous reverse transcriptase in murine early embryo development. Mol Reprod Dev 66: 225-236.

Platts AE, Dix DJ, Chemes HE, Thompson KE, Goodrich R, Rockett JC, Rawe VY, Quintana S, Diamond MP, Strader LF, et al. 2007. Success and failure in human spermatogenesis as revealed by teratozoospermic RNAs. Hum Mol Genet 16: 763-773.

Premkumar E, Bhargava PM. 1972. Transcription and translation in bovine spermatozoa. Nat New Biol 240: 139143.

Quattro JM, Avise JC, Vrijenhoek RC. 1992. Mode of origin and sources of genotypic diversity in triploid gynogenetic fish clones (Poeciliopsis: Poeciliidae). Genetics 130: $621-$ 628.

Rassoulzadegan M, Grandjean V, Gounon P, Vincent S, Gillot I, Cuzin F. 2006. RNA-mediated non-Mendelian inheritance of an epigenetic change in the mouse. Nature 441: $469-474$.

Rodgers AB, Morgan CP, Bronson SL, Revello S, Bale TL. 2013. Paternal stress exposure alters sperm microRNA content and reprograms offspring HPA stress axis regulation. J Neurosci 33: 9003-9012.

Saida M, Iles D, Elnefati A, Brinkworth M, Miller D. 2011. Key gene regulatory sequences with distinctive ontological signatures associate with differentially endonuclease accessible mouse sperm chromatin. Reproduction 142: 73-86.

Samans B, Yang Y, Krebs S, Sarode GV, Blum H, Reichenbach M, Wolf E, Steger K, Dansranjavin T, Schagdarsurengin U. 2014. Uniformity of nucleosome preservation pattern in mammalian sperm and its connection to repetitive DNA elements. Dev Cell 30: 23-35.

Sati L, Ovari L, Bennett D, Simon SD, Demir R, Huszar G. 2008. Double probing of human spermatozoa for persistent histones, surplus cytoplasm, apoptosis and DNA fragmentation. Reprod Biomed Online 16: 570-579.

Sciamanna I, Barberi L, Martire A, Pittoggi C, Beraldi R, Giordano R, Magnano AR, Hodgson C, Spadafora C. 2003. Sperm endogenous reverse transcriptase as mediator of new genetic information. Biochem Biophys Res Commun 312: 1039-1046.

Sciamanna I, Vitullo P, Curatolo A, Spadafora C. 2009. Retrotransposons, reverse transcriptase and the genesis of new genetic information. Gene 448: 180-186.

Sendler E, Johnson GD, Mao S, Goodrich RJ, Diamond MP Hauser R, Krawetz SA. 2013. Stability, delivery and functions of human sperm RNAs at fertilization. Nucleic Acids Res 41: 4104-4117.

Sironen A, Vilkki J, Bendixen C, Thomsen B. 2007. Infertile Finnish Yorkshire boars carry a full-length LINE-1 retrotransposon within the KPL2 gene. Mol Genet Genom 278: $385-391$.

Smith K, Spadafora C. 2005. Sperm-mediated gene transfer: Applications and implications. Bioessays 27: 551-562.

Soon LL, Breed WG. 1996. Ultrastructure of nuclear condensation and localization of DNA and proteins in spermatozoa of a dasyurid marsupial, Sminthopsis crassicaudata. Mol Reprod Dev 43: 217-227. 
D. Miller

Soon LL, Ausio J, Breed WG, Power JH, Muller S. 1997. Isolation of histones and related chromatin structures from spermatozoa nuclei of a dasyurid marsupial, Sminthopsis crassicaudata. J Exp Zool 278: 322-332.

Sotolongo B, Lino E, Ward WS. 2003. Ability of hamster spermatozoa to digest their own DNA. Biol Reprod 69: 2029-2035.

Tscherner A, Gilchrist G, Smith N, Blondin P, Gillis D, LaMarre J. 2014. MicroRNA-34 family expression in bovine gametes and preimplantation embryos. Reprod Biol Endocrinol 12: 85.

van der Heijden GW, Derijck AA, Ramos L, Giele M, van der Vlag J, de Boer P. 2006. Transmission of modified nucleosomes from the mouse male germline to the zygote and subsequent remodeling of paternal chromatin. Dev Biol 298: $458-469$.

van der Heijden GW, Ramos L, Baart EB, van den Berg IM, Derijck AA, van der Vlag J, Martini E, de Boer P. 2008 Sperm-derived histones contribute to zygotic chromatin in humans. BMC Dev Biol 8: 34.

Vavouri T, Lehner B. 2011. Chromatin organization in sperm may be the major functional consequence of base composition variation in the human genome. PLoS Genet 7: e1002036.

W.H.O. 1999. WHO laboratory manual for the examination of human semen and sperm-cervical mucus interaction. World Health Organisation.
Ward WS. 2010. Function of sperm chromatin structural elements in fertilization and development. Mol Hum Reprod 16: 30-36.

Ward MA, Ward WS. 2004. A model for the function of sperm DNA degradation. Reprod Fertil Dev 16: 547-554.

Witkin SS, Bendich A. 1977. DNA synthesizing activity in normal human sperm: Location and characterization of the endogenous reaction. Exp Cell Res 106: 47-54.

Wykes SM, Visscher DW, Krawetz SA. 1997. Haploid transcripts persist in mature human spermatozoa. Mol Hum Reprod 3: 15-19.

Yang CC, Lin YS, Hsu CC, Tsai MH, Wu SC, Cheng WT. 2010. Seasonal effect on sperm messenger RNA profile of domestic swine (Sus Scrofa). Anim Reprod Sci 119: $76-84$.

Zalenskaya IA, Bradbury EM, Zalensky AO. 2000. Chromatin structure of telomere domain in human sperm. Biochem Biophys Res Commun 279: 213-218.

Zhao Y, Li Q, Yao C, Wang Z, Zhou Y, Wang Y, Wang L, Qiao Z. 2006. Characterization and quantification of mRNA transcripts in ejaculated spermatozoa of fertile men by serial analysis of gene expression. Hum Reprod 21: $1580-1590$.

Zhao C, Guo XJ, Shi ZH, Wang FQ, Huang XY, Huo R, Zhu H, Wang XR, Liu JY, Zhou ZM, et al. 2009. Role of translation by mitochondrial-type ribosomes during sperm capacitation: An analysis based on a proteomic approach. Proteomics 9: 1385-1399. 


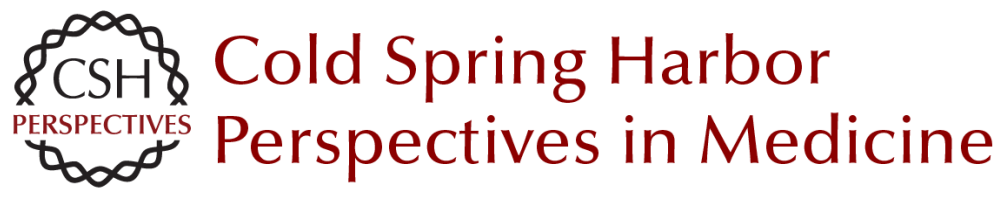

\section{Confrontation, Consolidation, and Recognition: The Oocyte's Perspective on the Incoming Sperm}

David Miller

Cold Spring Harb Perspect Med 2015; doi: 10.1101/cshperspect.a023408 originally published online May 8, 2015

Subject Collection Molecular Approaches to Reproductive and Newborn Medicine

Intergenerational Transfer of Epigenetic

Information in Sperm

Oliver J. Rando

\section{Effects of Maternal Obesity on Fetal Programming: Molecular Approaches Caterina Neri and Andrea G. Edlow}

The Neonatal Salivary Transcriptome Jill L. Maron

The Role of Hox Genes in Female Reproductive Tract Development, Adult Function, and Fertility Hongling Du and Hugh S. Taylor

\section{Molecular Cross-Talk at the Feto-Maternal Interface}

Gendie E. Lash

\section{Molecular Regulation of Parturition: A Myometrial Perspective \\ Nora E. Renthal, Koriand'r C. Williams, Alina P. Montalbano, et al.}

Genome-Wide Sequencing for Prenatal Detection of Fetal Single-Gene Disorders

Ignatia B. Van den Veyver and Christine M. Eng

MicroRNA in Ovarian Biology and Disease

Lynda K. McGinnis, Lacey J. Luense and Lane K. Christenson
A Molecular Perspective on Procedures and Outcomes with Assisted Reproductive Technologies Monica A. Mainigi, Carmen Sapienza, Samantha Butts, et al.

Whole-Exome Sequencing and Whole-Genome Sequencing in Critically III Neonates Suspected to Have Single-Gene Disorders

Laurie D. Smith, Laurel K. Willig and Stephen F. Kingsmore

Noninvasive Antenatal Determination of Fetal

Blood Group Using Next-Generation Sequencing Klaus Rieneck, Frederik Banch Clausen and Morten Hanefeld Dziegiel

Potential Uses and Inherent Challenges of Using Genome-Scale Sequencing to Augment Current Newborn Screening Jonathan S. Berg and Cynthia M. Powell

Molecular Regulation of Parturition: The Role of the Decidual Clock Errol R. Norwitz, Elizabeth A. Bonney, Victoria V. Snegovskikh, et al.

Molecular Mechanisms of Preeclampsia Tammy Hod, Ana Sofia Cerdeira and S. Ananth Karumanchi

Noninvasive Prenatal Screening for Genetic Diseases Using Massively Parallel Sequencing of Maternal Plasma DNA Lyn S. Chitty and Y. M. Dennis Lo

Confrontation, Consolidation, and Recognition: The Oocyte's Perspective on the Incoming Sperm David Miller

For additional articles in this collection, see http://perspectivesinmedicine.cshlp.org/cgi/collection/ 